\title{
Predicting Future Urban Housing Frontage Typology: Building Façade as the Interface of Transport, Logistics, and AEC 4.0
}

\author{
Arif Wismadi \\ Master of Architecture Program \\ Faculty of Civil Engineering and \\ Planning, Universitas Islam Indonesia \\ Sleman, Indonesia \\ wismadi@uii.ac.id
}

\begin{abstract}
Online parcel delivery service is one of the emerging evidences of Society 4.0 formation. In the near future, with increasing road traffic volume, night delivery to the houses become commonly found. The service is combined with e-money apps, IoT for logistics delivery compartment, and building automation that eliminate human interaction. This mechanism might lead to the evolution of housing façade as interface between secured interior and publicly accessible exterior environments. This trend presents a contradiction problem in designing façade of the houses, in which to ease the parcel delivery the interior must be as close as possible with the road; however, it might break the building set-back regulation. To predict the future typology of housing façade and frontage area a model solution of Contradiction Matrix from Altshuller was applied to investigate possible general solution to derive building typology. Based on the matrix analysis three Inventive Principles have been recommended, those are Asymmetry, Dynamics, and Another Dimension. For each principle a set of specific design was generated and evaluated based on the cost of parcel delivery, cost of double handling process and cost of regulation. Finally, the least cost solutions were used to predict the most acceptable housing frontage typology.
\end{abstract}

Keywords: future architecture, frontage typology, urban housing, transports, logistics

\section{INTRODUCTION}

The disruptive effect of Industry 4.0 has been emerging in many various fields, including Architecture, Engineering and Construction (AEC). Similar to the other industrial revolution waves such as the introduction of mechanical and steam powered as well as motorized engine that previously disrupted the typology and morphology of city formation due to human dependency to motorized vehicle [1] - , the industry 4.0 that hybrids physical, and digital system for processing human and industrial activity with support of automation and Internet-of-Thing (IoT) also has many implication that need to be anticipated.
Currently, many literatures has shared new knowledge on how ACE has been affected, such as Building Information Modelling [2], production process of architecture element in the factory, or building construction method in the field [3]. Illustration of how Industry 4.0 would change the shape of the city to be smarter, equipped with automation services, sensitized with sensors and optimize with adaptive big-data has been described in various publication [1].

Even though number of such references is increasing, it is still difficult to find a specific reference on how the Industry 4.0 might affect the typology and morphology of housing design. At the detailed level such as building component, application of IoT has been commonly found [4], even in the market. However, how it might influence form, space and façade typology has been overlooked. While in fact, many presences of Society 4.0 formed by the disruptive business model has been found.

Online parcel delivery service, for example, is one of the emerging evidence of Society 4.0 [5] formation. In the near future, with increasing road traffic volume, night delivery to the houses become commonly found [6]. The service is combined with e-money apps, IoT for logistics delivery compartment, and building automation that eliminate human interaction. This mechanism might lead to the evolution of housing façade as interface between secured interior and publicly accessible exterior environments. This trend presents a contradiction problem in designing façade of the houses, in which to ease the parcel delivery the interior must be as close as possible with the road; however, it might break the building set-back regulation.

The absent of such knowledge might lead to the property industry, such as housing and real estate to be behind the speed of Industry 4.0 movement. By disclosing the future trend housing morphology, architect will be exposed with new idea on how the housing typology should adapt with the trend. 


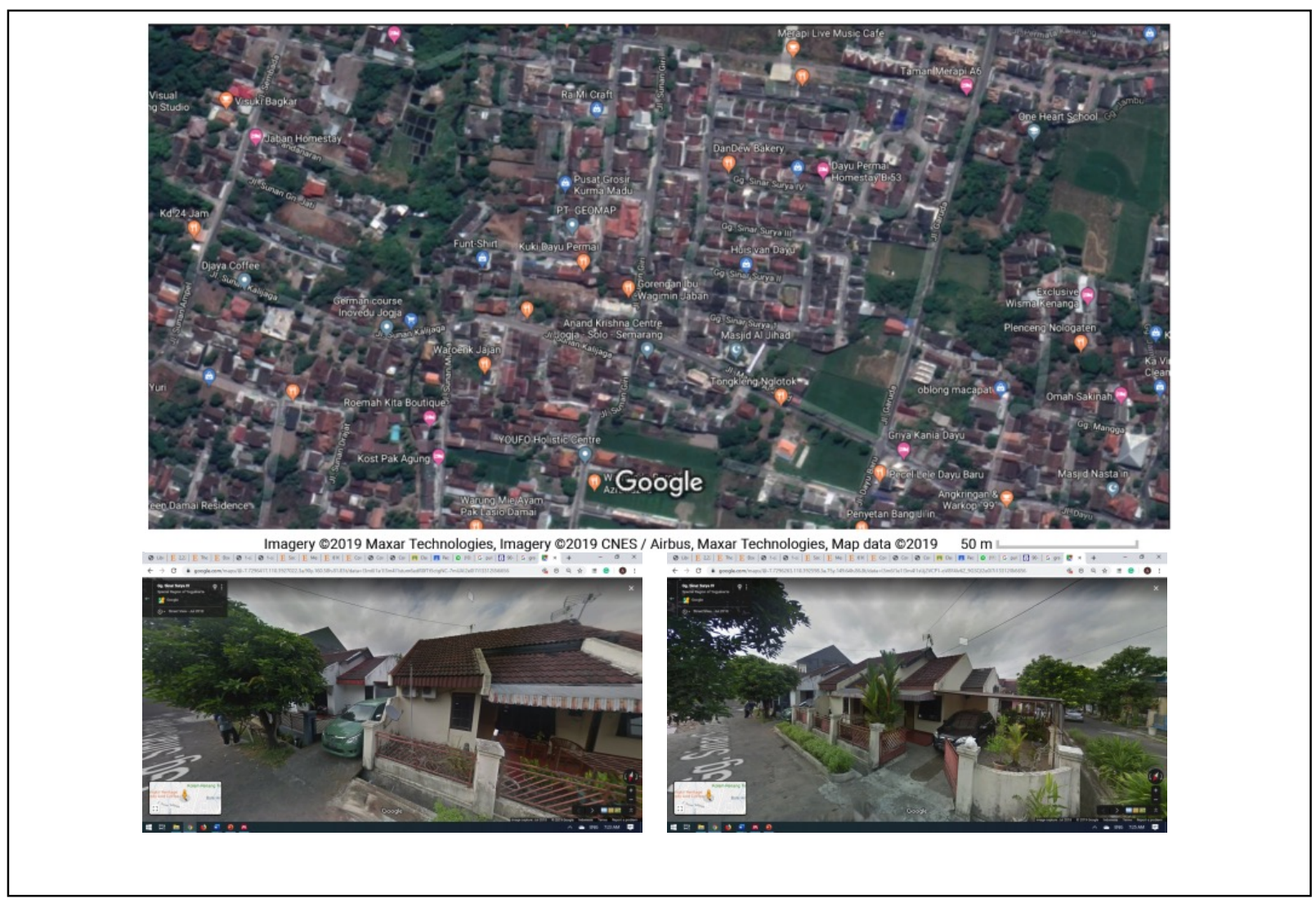

Fig 1. Study Area, the first real estate complex established on ' 80 , in the northern part of DI Yogyakarta.

The purpose of this study therefore was to discover the possibility on how future typology of housing façade due to the emerging parcel delivery mechanism derived from Industry 4.0. The prediction was start by exploring Trend of System Engineering Evolution (TESE) [7], followed by defining contradiction from domestic (private space) requirements and public (building code) requirements. To resolve the contradiction, we apply Altshuller's contradiction matrix [8] to find the general solution concept. A set of specific solutions was then formulated and compared to find the most preferred approach based on its cost of utility. The most efficient solution is then suggested as the predicted typology of house façade.

\section{METHOD}

\section{A. Research Design}

To predict the typology of housing façade due to the emerging parcel delivery mechanism derived from Industry 4.0, first we describe the future trend engineering system using TESE to illustrate how parcel delivery mechanism to each house would be performed. Based on the trend, new requirement of interior space arrangement for the house is defined. With the sample study from house type of 80's real estate property from northern part of Special Province of Yogyakarta that predominantly defined by car dependency mindset of modern movement, the new possible form, its morphology and resulting typology were illustrated. The new form design was determined by parcel delivery mechanism, the interior should as close as possible with road, but with anticipated implication of building code setback distance.
The anticipation of rule breaking of building set back while keeping the delivery mechanism was resolved with Inventive Principle selected in Altshuller' Contradiction Matrix. For each recommended Inventive principle, a set of faced design system was formulated and measured with the cost implication of parcel delivery. The cost comparison later was determined as the main criteria of selecting most predicted typology of housing façade.

\section{B. Material}

The sample study was obtained from house type of 80's real estate property from northern part of Special Province of Yogyakarta (DIY). The house type located in Perumahan Dayu Permai, which is considered as the first generation of real estate development in Yogyakarta. The type of house was replicated in various size from $54 \mathrm{~m}$-square to $120 \mathrm{~m}$ square. This replication that were predominantly defined by car dependency mindset of modern movement, such as car garage in the left or right side with capacity of 3 cars in a row, would be best illustrating a typology of houses affected by industry movement in modern era as seen in Figure 1.

\section{Measurement method}

The existing typology is then confronted with new requirement determined by parcel delivery under Industry 4.0 model. Therefore, a set of new possible forms, its morphology and resulting typology were generated.

The new form design was aimed to solve the contradiction determined by parcel delivery mechanism -the interior should as close as possible with road, to minimized cost of delivery- but with anticipated implication of building code setback distance. 
Therefore, to measure which approach is the most possible solution will be adopted by society is cost of time delivery at point of double handling from exterior to the interior of the building.

\section{Calculation}

The anticipation of rule breaking on building set-back code, while keeping the delivery mechanism was resolved with Inventive Principle selected in Altshuller's Contradiction Matrix. For each recommended Inventive Principle, a set of façade design system was formulated and measured with the cost implication of parcel delivery. The cost comparison later was determined as the main criteria of selecting most predicted typology of housing façade.

The calculation was performed with the basic formula described as:

$$
C=1 / n\left(\sum_{i=0}^{n}(c E+c D+c I)\right)
$$

where:

\section{$\mathrm{C}$ : average cost of delivery from each set of typologies}

cE: cost of exterior section delivery (Second), obtained from distance of the road to logistic compartment divided by walking speed ( $5 \mathrm{kms}$ per hours)

$\mathrm{cD}$ : cost of double handling between exterior and interior (Second), estimated time required from handling the goods by parcel officer into logistic compartment and handed over by house owner

cI: cost of interior section delivery (Second) estimated time required to transfer the goods from logistic compartment to in-house storage systems.

\section{E. Analysis}

To determine the most preferable typology, the least cost design objective was applied. Therefore, comparison of $\mathrm{C}$ of each set typology is the main analytical approach to predict the future typology.

\section{RESULTS}

\section{A. Trend of Logistic Delivery and the Contradiction Caused.}

To predict the evolution of logistic delivery due to the disruption of Industry 4.0, the Trends of Engineering System Evolution (TESE) was applied. This method is based on statistically proven direction of Engineering Systems development that describe the natural transition from one state to another.

The TESE that is based on analysis of patents and technology history aims to higher uplift productivity and lower risk, which has been utilized by both technicians and business planners to forecast future changes in technology (see Figure 2.).

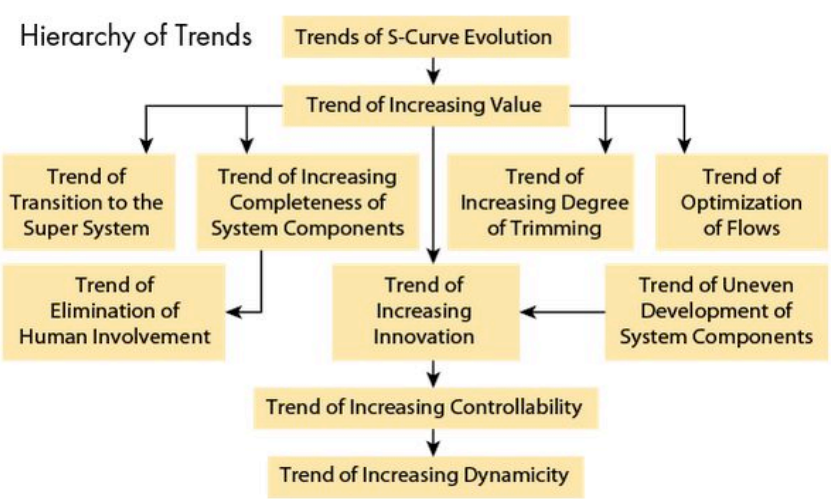

Fig 2. Trends in Engineering System Evolution [9]

Each of these Trends can be identified and examined at a given stage of technology evolution, to anticipate the likely directions of future changes in a system or platform. The trends are not necessarily sequential or mutually dependent; rather, they tend to occur in parallel, to varying degrees, depending on the nature of the system and its stage of development.

The S-Curve describe that new system would born and grow slowly at the first stage, then increase rapidly as the second stage, and reach the peak as it applied widely in the $3^{\text {rd }}$ stage, before it slowly decreased in demand as new other systems is born and disrupting the existing one.

With the presence of Industry 4.0, logistic delivery's value at household level could increase rapidly to be faster, cheaper and better in quality of service. On the system side, supplier of goods that previously own their logistic service is then outsourcing to external (or to the Super System) for efficiency objectives.

All logistic component would be more completed to from procurement to its downstream delivery to the end consumer as well as the upstream component back to the factory for reuse, recycling or upcycling process. Even, with the IoT technology, all the process and component could eliminate human involvement.

Unnecessary component of the systems, on the other hand will be trimmed, e.g. warehouse is shrinking or even skipped due to JIT (just-in-time) application supported by IT systems. The JIT also optimize the flows of goods, information and money.

The innovation also increases, unevenly with focus to only the special and significant systems component, e.g. cloud-based platform and trim all the vehicle by outsourcing to the $3^{\text {rd }}$ parties. The platform will power the system controllability as well as the dynamic of the systems, including pricing policy and service enhancement.

At the household level, the evolution could be illustrated as fully automated logistics supply chain management (LSCM) embedded in the kitchen, refrigerator, and all storage components equipped with sensitive IoTs that linked to the e-money or e-banking systems. Human involvement might be more on the enjoyable cooking and other depth personal experiences.

On the housing design aspect, some of new ideas of spatial arrangement may emerge. With the Logistics 4.0, new 
3. Referring to Altshuller's Contradiction Matrix, a cell from Row (3) "Length of moving object" and Column (5) "area of moving object" suggest three Inventive Principle (IP) no 4 "Asymmetry', no 15 "Dynamic" and 17 "Another Dimension" as the general solution.

efficient require a smooth, and fast transition to drop the parcel or pick-up the upstream delivery. Therefore, the logistics compartment should be at the closest distance to the road or public access. In this case, however, the compartment should be within the interior of the house.

On the other hand, human activity that more dependent to the automation systems, tend to be more less active. For example, in processing the double handling process of delivered parcel, the house owner prefers the closest distant between logistics compartment to the in-house storage systems.

In such a case, house design, at the interface part between public and private space, or the façade, will be required to resolve the contradiction of closest distant to the public space, as well as the private space. At the same time, there is a building code that define building set-back at the appropriate distance.

Following the approach in the Theory of InventiveProblem Solving (TRIZ), the contradiction could be define as Engineering Contradiction (EC) of Physical Contradiction (PC) [7]. The EC could be modelled with the structure of problem statement of IF, THEN, BUT. While the PC could be modelled as "Should be A" and "Should be Non-A" [8].

Therefore, the EC in this house façade design could be defined as "IF the façade is close to the road, THEN the logistic process is very efficient, BUT the building breaks the set-back regulation". Meanwhile, the PC could be described as "The façade should be close to the road to make the logistic process so efficient, AND the façade should be far to comply with building set-back regulation".

\section{B. Resolved Contradiction: General Solution}

TRIZ method solves the contradiction with following steps:

1. Define specific problem

2. Define the general problem

3. Seek for the general solution

4. Develop the specific solution

Resolved EC with Altshuller's Contradiction Matrix

1. The specific problem is defined as "IF the façade is close to the road, THEN the logistic process is very efficient, BUT the building breaks the set-back regulation"

2. The generic problem is defined by selecting the closest analogy of the attribute in the specific problem with the parameter selected from the 39 System Parameters. Therefore the attribute of "the logistic process is very efficient" defined as Improving Parameter of "(3) Length of moving object", while the attribute of "the building breaks the set-back regulation" is defined at the Worsening Parameter of "(5) area of moving object".

4. Based on the suggested Inventive Principle the possible specific solution that represent the possible design of housing façade are as follow.

\section{Specific Solution}

Possible generated typology includes:

Asymmetry: Left (L) or Right (R), the logistic compartment located at the left or right side of the facade

Dynamic: Active (A) or Passive (P), the dynamic component could be active and required electricity or passive and rely of gravity

Another Dimension: Above (A) or Below (B), the logistic compartment located above the level, or below (underground).

The alternative of façade designs therefore are:

RAA, RAB, LAA, LAB, RPA, RPB, LPA, LPB

Figure 3-5 illustrate the option of specific solution that influence the building frontage and its typology.

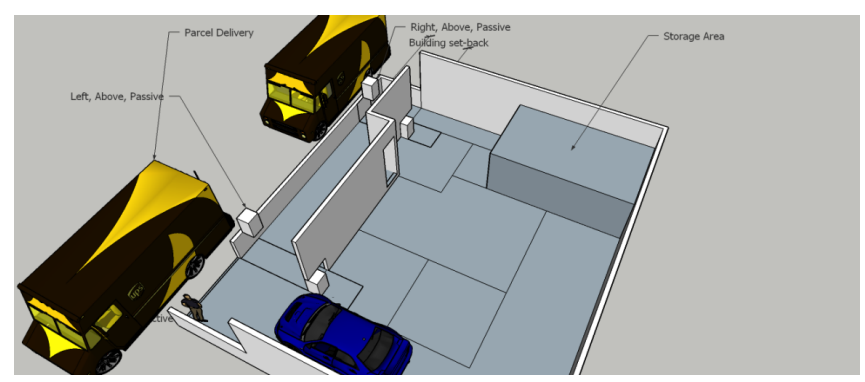

Fig 3. Asymmetry: Left (L) or Right (R), the logistic compartment located at the left or right side of the façade

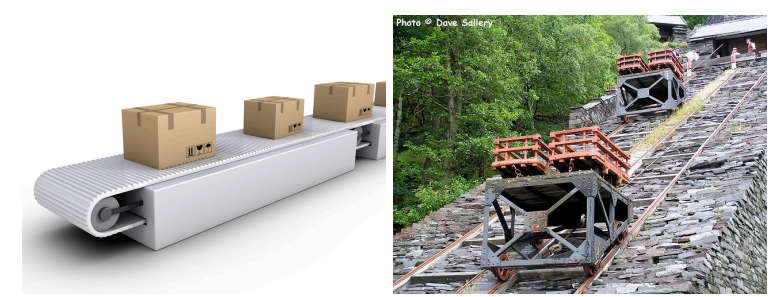

Fig 4. Dynamic: Active (A) or Passive (P), the dynamic component could be active and required electricity or passively rely of gravity

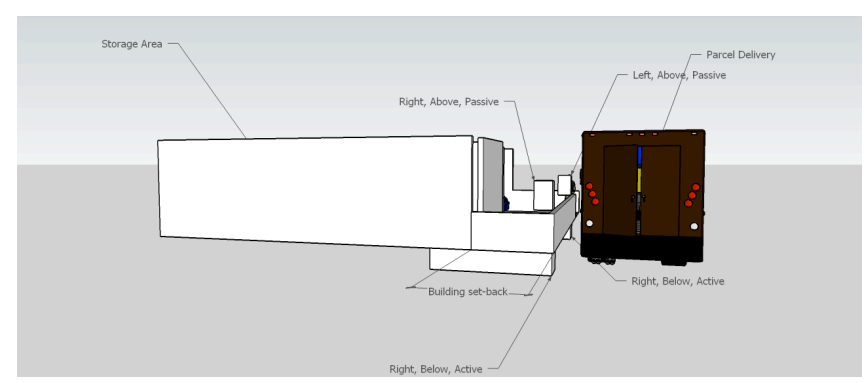

Fig 5. Another Dimension: Above (A) or Below (B), the logistic compartment located above the level, or below (underground) 


\section{The Cost of Each Typology}

Cost of delivery (time) for each alternative is summarized in the following table.

The $\mathrm{cE}$ is exterior delivery cost consist of process of stop - open the door of vehicle - open the door of compartment take the parcel - load the parcel to the compartment - close the container.

The cD stands for double handling cost, consist of the process of opening the lock of the container-take the parcellock back the container - bring to the interior side.

The cI is cost of time for transferring from exteriorinterior transition to the in-house storage.

TABLE I. COST SUMMARY (SECONDS)

\begin{tabular}{|c|c|c|c|c|}
\hline & $\mathbf{c E}$ & $\mathbf{c D}$ & $\mathbf{c I}$ & $\mathbf{C}$ \\
\hline RAA & 29 & 19 & 24 & 72 \\
\hline RAB & 27 & 21 & 55 & 103 \\
\hline LAA & 29 & 37 & 52 & 118 \\
\hline LAB & 27 & 39 & 55 & 121 \\
\hline RPA & 32 & 12 & 17 & 61 \\
\hline RPB & 30 & 39 & 20 & 89 \\
\hline LPA & 32 & 30 & 45 & 107 \\
\hline LPB & 30 & 57 & 48 & 135 \\
\hline
\end{tabular}

IV. DISCUSSION

Using TESE and Altshuller Contradiction Matrix the possibility on how future typology of housing façade due to the emerging parcel delivery mechanism derived from Industry 4.0 has been discovered with the most efficient typology of asymmetric façade with dynamic-passive of logistic compartment located above the ground level.

House typology represent by RPA has the least cost logistic delivery (61 seconds). Asymmetric placement of logistic delivery compartment near to service and storage area are preferable, the passive pulley system with gravity powered movement could dynamically convey the delivery from exterior part and efficiently deliver into interior part of the house. This system could significantly reduce the cost for moving the delivery into the in-house storage, in this case study is at R (right side). The passive system also minimizes operation cost and energy consumption.

The only drawback of the RPA is the required slope to enable gravity energy to pull-down the loaded compartment and lift-up the upstream logistic of empty box-and-bottle to further reuse-recycle-upcycle process. The required slope needs certain elevation of A (above) the ground level and add more cost or effort to lift the parcel at the higher level. This elevation limits the maximum distance from exterior or publicly accessible area to the interior of the house. In this case study, or in the common building coverage ratio (BCR) of urban settlement, the building set-back could be reached with the non-assistive handing process to move and lift the parcel into above-the-ground logistic compartment.

Learning from the observation process and the finding, this study could contribute in exploring the idea on how the movement of Industry 4.0 could affect AEC, not only in manufacturing process but also in taking into account new aspect of housing design and smart city development [1].
Moreover, the method of TRIZ applied in this study could illustrate a systematic process to generate new idea and invention in architectural design where contradictionproblems present and need to be resolved.

\section{REFERENCES}

M. Nilssen, "Technological Forecasting \& Social Change To the smart city and beyond? Developing a typology of smart urban innovation," Technol. Forecast. Soc. Chang., vol. 142, no. December 2017, pp. 98-104, 2019.

[2] P. Piroozfar, E. R. P. Farr, L. Hvam, D. Robinson, and S. Sha, "Automation in Construction Configuration platform for customisation of design, manufacturing and assembly processes of building façade systems: A building information modelling perspective," vol. 106, no. July, 2019.

F. Bianconi, M. Filippucci, and A. Buffi, "Automation in Construction Automated design and modeling for masscustomized housing. A web-based design space catalog for timber structures," Autom. Constr., vol. 103, no. May 2018, pp. 13-25, 2019.

J. Shah and B. Mishra, "Customized IoT enabled Wireless Sensing and Monitoring Platform for Smart Buildings," Procedia Technol., vol. 23, pp. 256-263, 2016.

N. Janse, V. Rensburg, A. Telukdarie, and P. Dhamija, "Technology in Society Society 4.0 applied in Africa: Advancing the social impact of technology," Technol. Soc., no. April, pp. 1-12, 2019.

[6] R. Slávik and J. Gnap, "ScienceDirect ScienceDirect Selected Time Time Distribution Distribution of of Goods Goods within within City City Selected Problems Problems of of Night Night Logistics Logistics," Transp. Res. Procedia, vol. 40, no. Transcom, pp. 497-504, 2019.

[7] Y. T. San, Y. T. Jin, and C. C. Li, TRIZ - Systematic Innovation in Manufacturing, 1st ed. Selangor Darul Ehsan: First Fruits Sdn. Bhd., 2016.

[8] Y. T. San, TRIZ Level 3 Training Manual. Selangor: Inno Planet Sdn. Bhd, 2017.

[9] Y. T. San, TRIZ - Systematic Innovation in Business \& Management: . First Fruits Sdn. Bhd., 2014. 